\title{
Ethnographic beliefs in Hong Kong
}

\author{
Physiognomy and teeth: An ethnographic study among young and middle-aged Hong Kong adults
}

\section{McGrath, K. S. Liu and C. W. Lam Br Dent J 2002; 192: 522-525}

\section{Objectives}

To determine knowledge and beliefs about traditional physiognomy (judging an individual's character from their facial appearance) concerning teeth among young (17-26) and middle-aged (35-44) Hong Kong adults.

\section{Methods}

In a cross sectional ethnographical telephone survey, 400 adults were interviewed about 16 traditional physiognomy concerning teeth (in consultation with a Feng Shui specialist).

\section{Results}

Most completed the interview $(93 \%, 373)$. Over half the study group $(63 \%, 234)$ claimed they had heard of aspects of physiognomy concerning teeth, and a quarter $(24 \%, 88)$ believed in such ideologies. Variations in knowledge and beliefs were apparent among people of different age $(\mathrm{P}<0.01)$, gender $(\mathrm{P}<0.05)$, educational attainment $(\mathrm{P}<0.01)$, economic status $(\mathrm{P}<0.01)$, place of birth $(\mathrm{P}<0.01)$ and religion $(\mathrm{P}<0.01)$. Their knowledge and belief in aspects of physiognomy concerning teeth was also associated with reported use of dental services $(\mathrm{P}<0.01)$.

\section{Conclusion}

Among young and middle-aged adults in Hong Kong, knowledge and beliefs concerning traditional physiognomy regarding teeth is strong, and socio-demographic variations exist in these perceptions. These findings have implications for all those involved in the delivery of dental care in multicultural societies and in raising cultural awareness about traditional health beliefs.

\section{IN BRIEF}

- Physiognomy is the judging of an individual's character from their facial appearance. This practice exists in many cultural groups and notably among Chinese groups.

- There are a number of aspects about teeth that are used in physiognomy. This study explored whether young Chinese adults in Hong Kong 'heard about' and 'believed in' dental aspects of physiognomy.

- This paper raises an awareness of traditional health beliefs and ideologies that are of interest to all those delivering care in multicultural environments.

\section{COMMENT}

The practice of face-reading can be dated back to ancient Greece but is still popular today in some parts of the world, as is evident from the findings presented by McGrath and colleagues.

Their study surveyed a sample of Hong Kong Chinese adults by telephone interviews using a fully structured questionnaire and concluded that the prevalence of beliefs in physiognomy and teeth is high, which in turn is associated with use of dental services. Although they have described their study as ethnographic, a structured questionnaire survey is strictly not an ethnographic study. ${ }^{1}$ Ethnography involves a triangulated approach to research in which qualitative data are generated to validate certain observations or phenomena. Nonetheless, the finding that physiognomic beliefs related to teeth are prevalent is an important one.

Physiognomy, the art of reading personality traits from faces, is a fascinating subject. Personality information conveyed in faces, through non-verbal communication, changes the interpretation of verbal information. ${ }^{2}$ Further, physiognomic measurements are used to guage analogous deformations of the soul and draw moral conclusions. ${ }^{3}$ On the other side of the coin, pathognomy recognises that uneven physical features may indicate humanity instead of character flaws. This study will hopefully stimulate further investigation into the role that our visual and perceptual preferences play in our judgements concerning what is normal and what is anomalous. The judgments we make based on physiognomic assessment may influence our behaviours in relation to dental health, as McGrath and colleagues suggest. However, the data linking physiognomic beliefs to use of dental services should be interpreted with caution as the number of people reported to have used dental services because of physiognomic reasons is small.

A common feature of human behaviour is our tendency to believe in something but not to translate that belief into action. The link between physiognomic beliefs and care-seeking behaviours may be the impact that such beliefs have on social and economic opportunities. Thus in a society where such beliefs are prevalent, a person with missing incisors or spaces between their front teeth may be less likely to find a marriage partner or find employment. An important implication of the findings reported is for dental practitioners to be aware and sensitive to the reasons for patients' complaints, for these reasons may well have substantial impact on their lives.

Allan Pau, Lecturer in Dental Public Health Barts and The London

Bowling A. Research Methods in Health. Buckingham: Open University Press, 1997.

2. Hassin $R$, Trope $Y$. Facing faces: studies on the cognitive aspects of physiognomy. J Pers Soc Psychol 2000; 78: 837-52.

3. Stafford BM, La Puma J, Schiedermayer DL. One face of beauty, one picture of health: the hidden aesthetic of medical practice. J Med Philos 1989; 14: 213-30. 